\title{
Fenomenologia, psicoterapia e psicologia humanista
}

\author{
Adriano Holanda* \\ Pontifícia Universidade Católica de Campinas
}

O texto introduz as idéias básicas da Fenomenologia como fundamento filosófico e epistemológico para a prática da psicoterapia e, mais especificamente, da psicologia humanista. Parte da gênese histórica das idéias fenomenológicas em Brentano, passando à elaboração da Fenomenologia no pensamento de Husserl, apresentando seus principais conceitos. Neste contexto, estabelece um paralelo entre o método fenomenológico e suas aplicações no campo da psicoterapia. Por fim, elabora um quadro geral da influência da Fenomenologia e do Existencialismo na chamada "Psicologia Humanista", destacando os principais expoentes deste movimento.

Palavras-Chave: Fenomenologia, Psicologia Humanista, Psicoterapia, Consciência, Intencionalidade.

\begin{abstract}
Fenomenology, Psychoterapy and Humanist Psychology

The text makes an introduction to the basic ideas of the Phenomenology like a philosophical and epistemological foundation to the practice of psychotherapy and most specifficaly, of the humanistic psychology. It begins by the historical genesis of the phenomenological ideas in Brentano, and continues by the elaboration of Phenomenology in the thinking of Husserl, presenting its mains concepts. In this way, it stablishes a parallel between the phenomenological method and its application to psychotherapy. Finally, it makes a generic picture of the influence of Phenomenology and Existentialism to the "Humanistic Psychology", detaching the principals names of this movement.

Key words: Phenomenology, Humanistic Psychology, Psychotherapy, Conscience, Intentionality.
\end{abstract}

A Fenomenologia representa um marco na história da Filosofia, podendo ser comparada a autênticas "revoluções paradigmáticas" como a socrática, a cartesiana e a kantiana. Sua penetração no âmbito da Psicologia é de fundamental importância para se entender a totalidade da relação psicoterapêutica e da psicopatologia.

A importância da Fenomenologia se caracteriza pelo resgate da subjetividade na Filosofia e nas demais ciências humanas. O compromisso de Husserl com o pensamento de Descartes torna a Fenomenologia uma corrente

\footnotetext{
* Psicólogo, Psicoterapeuta com Formação em Facilitador na Abordagem Centrada na Pessoa e Gestalt-Terapia de Grupos, Mestre em Psicologia Clínica pela Universidade de Brasília (UnB), Doutorando em Psicologia pela Pontifícia Universidade Católica de Campinas (PucCampinas).

Endereço para correspondência: SQN 309, bloco B, apto 214, CEP 70755-020, Brasília, DF, FONE: (061) 983.4126.

1. Figueiredo, 1991.
}

de pensamento imprescindível para a própria compreensão da cultura e da evolução do nosso século.

Husserl era um profundo admirador da filosofia de Descartes. Todavia, considerava que Descartes não havia aprofundado suficientemente sua investigação epistemológica. ${ }^{1} \mathrm{Seu}$ "compromisso" com Descartes consiste no seu projeto de tornar a Filosofia uma "ciência rigorosa", semelhante à idéia cartesiana. Em complemento a isto, podemos citar o próprio Husserl, quando escreve que:

$$
\text { "Com efeito, nenhum filósofo }
$$
do passado teve uma influência tão decisiva sobre o sentido da fenomenologia como o maior pensador da França, René Descartes. É a ele que ela deve venerar como seu verdadeiro patriarca. Foi de um modo muito direto, diga-se expressamente, que o 
estudo das meditações cartesianas interveio na nova configuração da fenomenologia nascente $e$ lhe deu a forma de sentido que agora tem e que quase lhe permite chamar-se um novo cartesianismo, um cartesianismo do século $X X^{\prime \prime}, 2$

Para realizar seu projeto, Husserl parte de Descartes para criticá-lo no estabelecimento de um subjetivismo solipsista ${ }^{3}$ caracterizado por uma consciência definidora, mas que esquece os objetos e as relações que esta consciência estabelece com o mundo.

O projeto de Husserl é de tornar a Filosofia o fundamento básico de todo conhecimento, ou mais especificamente, fazer da Filosofia uma "ciência de rigor", tomando por base as matemáticas. "[A] Fenomenologia se preocupa essencialmente com o rigor epistemológico, promovendo a radicalização do projeto de análise crítica dos fundamentos e das condições de possibilidade do conhecimento". 4

Além disso, a Fenomenologia, como método, possibilitou o advento de uma forte corrente de pensamento européia, cujo legado ainda está para ser avaliado: o Existencialismo, ${ }^{5}$ com todas suas conotações e diversificações. Esta abordagem de pensamento é muito bem representada em nosso século por figuras como Martin Heidegger, Jean-Paul Sartre, Karl Jas- pers, Gabriel Marcel, Martin Buber e Emmanuel Lévinas, apenas para citar alguns.

\section{Fenomenologia: gênese e evolução histórica}

O que entendemos hoje como Fenomenologia diz respeito a uma corrente de pensamento cujas raízes estão calcadas na preocupação: preocupação com os rumos da ciência e com a colocação do ser humano nesta situação.

Fenomenologia é uma filosofia, se a entendemos de maneira original. Todavia, antes de se caracterizar como um modo específico de pensamento, antes de se constituir numa forma sistemática de se acessar a realidade, a Fenomenologia é um método, uma metodologia de pesquisa dessa mesma realidade, e como tal implica uma específica visão de mundo.

Originalmente, diríamos que a Fenomenologia é um retorno, um "recomeço radical", uma retomada do sentido exato do vocábulo grego phainómenon, que significa "aquilo que vem à luz", que "se mostra", é a manifestação daquilo que se esconde. Historicamente, o phainómenon era para os astrônomos gregos, a referência aos eventos celestes.

A expressão "Fenomenologia" à qual nos referimos não é aquela utilizada por Hegel quando escreve sua obra $A$ Fenomenologia do

2. Husserl, 1992:9.

3. Husserl assinala nas suas Conferências de Paris (1992) que o ego cartesiano realiza "um filosofar seriamente solipsista". "Solipsismo" advém de solus-ipse, e designa uma consciência que se fecha sobre si mesma.

4. Figueiredo, 1991:172.

5. Isto pode ser ilustrado por um episódio ocorrido com Sartre. Conta Simone de Beauvoir que em certa ocasião, estavam, juntamente com Raymond Aron num bar e este teria se dirigido a Sartre dizendo: " 'Como vê, meu caro, se você é um fenomenologista, é capaz de falar deste coquetel e fazer filosofia dele '. Narra de Beauvoir que Sartre empalideceu de emoção diante do que ouviu. Era isso o que ele procurava há vários anos: 'descrever os objetos como os via e tocava' e disso 'extrair' filosofia" (Penha, 1996:20). 
Espirito; mas refere-se à metodologia idealizada pelo filósofo alemão Edmund Husserl. ${ }^{6}$

A figura de Husserl é central dentro desta consideração, podendo ser considerado um marco na filosofia do século XX. Suas idéias foram determinantes diretas dos pensamentos de filósofos como Sartre, Heidegger, MerleauPonty e outros.

A história de Husserl é marcada por situações de considerável relevância. De origem judaica, foi proibido de publicar durante o período de governo do III Reich; suas obras somente foram publicadas integralmente em 1950 na cidade de Haia, na Holanda e, segundo alguns autores, graças aos esforços de alunos seus que conseguiram, clandestinamente, evitar a queima de seus manuscritos enviando-os para fora da Alemanha.

A gênese da Fenomenologia, contudo, se dá através da figura de Franz Brentano, alemão nascido em Marienberg. Em 1874, publica sua obra capital: Psicologia do Ponto de Vista Empírico, fato este importante devido à posterior influência que terá sobre Husserl o pensamento deste filósofo. Brentano "foi representante de uma psicologia descritiva a qual chamou de 'psicologia dos atos', que considera o essencial das manifestações anímicas (atos) em sua relação com o objetivo ao qual estão encaminhadas (intencionalidade)". ${ }^{7}$ Foi sacerdote católico, tendo se ordenado em 1864, mesmo ano de seu doutoramento em Filosofia. Entrou em confronto com a Igreja por não aceitar o dogma da infalibilidade papal, tendo por isto se retirado de sua cátedra em 1873 e se convertido ao protestantismo em 1879. Dentre seus discípulos destacamse Christian von Ehrenfels, ${ }^{8}$ Edmund Husserl e Oswald Külpe, sendo que Freud tomou algumas lições com ele (mais especificamente durante os anos de 1874-1876). ${ }^{9}$ O fundamental da psicologia brentaniana é que a experiência se baseia na percepção interior, ao contrário do que propunham os sistemas psicológicos primevos ao apontar para a introspecção (observação interior). Com isto reage contra a análise dos conteúdos da consciência conforme a psicologia experimental de Wilhelm Wundt e contra a orientação naturalista tomada de empréstimo à física e à fisiologia.

6. O termo "Fenomenologia" refere-se "à descrição do que aparece ou à ciência que tem como tarefa ou projeto esta descrição" (Abbagnano, 1992:531). O termo é antigo, tendo sido usado por Lambert no seu Novo Órganum (1764), que a considerava o estudo das fontes do erro. Já Kant adota o termo para designar "a parte da teoria do movimento que considera o movimento ou o repouso da matéria somente em relação com as modalidades em que aparecem ao sentido externo" (Abbagnano, 1992:531-532). Hegel também utiliza o termo como título de uma de suas obras capitais, A Fenomenologia do Espirito. Neste sentido, a palavra Phaënomenologie é usada por Hegel para designar "a totalidade dos fenômenos da mente na consciência, na história e no pensamento. (...)" Husserl empregou a palavra, de início, para referir-se à "psicologia descritiva" dos fenômenos da consciência (...). Para nós, a fenomenologia é um procedimento empírico, que só se mantém pelo fato da "comunicação da parte dos pacientes" (Jaspers, 1987:71). Outros autores fizeram uso do termo, como por exemplo Hamilton que a entendeu como psicologia descritiva; ou E.von Hartmann que a associou à "Fenomenologia da Consciência Moral". Todavia, a noção que permanece mais viva é justamente a utilizada por Husserl baseada em suas Investigações Lógicas.

7. Bonin, 1991:68.

8. Importante personalidade da Psicologia. Foi precursor da chamada Gestalt-Theorie ou a Psicologia da Gestalt, influenciando diretamente as figuras de Köhler, Koffka e Wertheimer.

9. A propósito, existe uma série de semelhanças entre Husserl e Freud: ambos nasceram na Morávia, Freud em 1856 e Husserl em 1859; estudaram em Viena, na mesma época, embora não existam informações de que tenham se encontrado, Freud se doutorou em $1881 \mathrm{e}$ Husserl em 1882. Ambos publicaram suas obras capitais no ano de 1900 (Freud com A Interpretação dos Sonhos e Husserl com suas Investigações Lógicas). Ainda sobre a correlação entre Freud e Husserl, assinala Bucher (1983:34): “...curiosamente, ambos os pensadores iniciam as suas pesquisas com uma inovação metodológica pela qual se destacam de todas as escolas e autores precedentes, e que merece ser chamada de corte epistemológico, com todas as implicações que tem essa noção, de revolução, senão de 'subversão' das idéias vigentes até aí..". 
Husserl nasceu na cidade de Prostnitz, na Morávia, em 1859; entre os anos de 1876 a 1878 freqüenta e se gradua em Matemática pela Universidade de Leipzig. Baseado na obra de Brentano, Husserl desenvolve grande parte de suas idéias. Em 1882, Husserl obtém seu doutoramento na Universidade de Viena com a tese "Sobre o Cálculo das Variações". No ano seguinte, em Berlim, torna-se assistente de um exprofessor seu, Weirtrass. Em 1884, Husserl retorna a Viena e se filia ao pensamento de Brentano. Dois anos depois renuncia à sua ascendência judaica, convertendo-se ao Luteranismo, casando no ano seguinte com Malvine Steinschneider. Posteriormente torna-se livredocente pela Universidade de Halle. Começa aí sua vida intelectual realmente produtiva.

No ano de 1891 publica o primeiro volume da sua Filosofia da Aritmética, obra que ficou inacabada. Entre os anos de 1900-1901, publica uma de suas obras capitais: Investigações Lógicas. Cresce sua consideração, tanto que, em 1906, é nomeado professor da Universidade de Göttingen. Seus cursos sempre foram fonte de questionamento e de desenvolvimento de suas idéias. No ano de 1907, durante seu curso sobre "A Idéia da Fenomenologia", surge-lhe a primeira idéia explícita sobre a redução.

Seguem-se suas publicações mais fundamentais: em 1910, A Filosofia como Ciência Rigorosa; três anos mais tarde é a vez de Idéias para uma Fenomenologia Pura e para uma Filosofia Fenomenológica, em que propõe uma investigação da consciência e de seus objetos. No ano de 1914, irrompe a Primeira Grande Guerra e, no ano seguinte, seu antigo discípulo, Heidegger, ocupa a cadeira de livre-docente na
Universidade de Freiburg. No ano de 1929 publica Lógica Formal e Transcendental; em 1931, reunidas suas conferências sobre a filosofia cartesiana, é publicada, na França, as Meditations Cartésiennes; e em 1936 é a vez de $A$ Crise das Ciências Européias e a Fenomenologia Transcendental. Após muitas dificuldades, Husserl vem a falecer em 1938, deixando muita influência sobretudo nos pensamentos de Martin Heidegger, Max Scheler, Jean-Paul Sartre e Maurice Merleau-Ponty.

\section{Fenomenologia: tentativa de definição}

Definir claramente o que vem a ser a Fenomenologia talvez seja tarefa demasiado árdua. $\mathrm{Na}$ realidade, o próprio conceito de definição carrega uma conotação de algo estático que ignora a própria essência do termo.

O problema da Fenomenologia é um problema de fundamentação da ciência. Husserl estabeleceu para si a tarefa de repensar os fundamentos. Eugen Fink, um eminente conhecedor do pensamento husserliano, aponta a fenomenologia como um "recomeço radical", uma retomada da busca das raízes. Constitui-se numa tentativa de superação da dicotomia sujeito/objeto, através da apreensão das relações do homem com o mundo. ${ }^{10}$

A Fenomenologia surge como uma criti$c a$, no sentido original do termo, ${ }^{11}$ como uma tentativa de pôr em crise o conhecimento vigente. Assim, surge como crítica à psicologia positivista, objetiva, experimental que, como as demais ciências, buscava o conhecimento absoluto ignorando a subjetividade.

10.Relações do homem com o Umwelt (mundo ambiente), Mitwelt (mundo humano) e o Eigenwelt (mundo próprio). 11. Sobre a questão da "crítica" uma citação serve de esclarecimento: "O termo 'crítica' (..) foi aqui encarado no sentido originário de uma interrogação sobre as condições de possibilidade e os limites de algo (..). Nesse sentido, a crítica se caracteriza, não pela mera objeção pessoal ou pela apreciação que destaca as qualidades e os defeitos de uma obra ou de uma posição, mas por uma busca de fundamentos, isto é, por certo modo de reflexão que, ultrapassando a experiência imediata, ruma para o ser, encontrando ai a origem da primeira" (Frayze-Pereira, 1984:1. Grifos nossos). 
Ao propor isto, a ciência constrói uma imagem de homem que não condiz com sua realidade. O homem não é uma coisa entre as coisas, e como tal não pode assim ser considerado. O mundo é um objeto intencional com referência a um sujeito pensante, o que invalida a objetividade absoluta.

A Fenomenologia se opõe também ao naturalismo, que assinala o comportamento como uma mera relação causa e efeito; e ao idealismo de Kant e Hegel, que propunha o homem como um conjunto conceptual organizado.

No prefácio de seu livro Phénoménologie de la Perception, o filósofo francês Maurice Merleau-Ponty — principal personagem da Fenomenologia pós-husserliana — propõe a questão:

"O que é a fenomenologia? (..) É o estudo das essências... Mas a fenomenologia é também uma filosofia que recoloca as essências na existência e não pensa que seja possível compreender o homem e o mundo de outra forma que não seja a partir de sua facticidade. É uma filosofia transcendental, que põe em suspenso para compreender as afirmações da atitude natural, mas é ainda uma filosofia para a qual o mundo está sempre aí, antes da reflexão, como uma presença inalienável...",12

A Fenomenologia é um esforço, uma tentativa de clarificação da realidade humana. É uma abertura à experiência, à vivência integral do mundo. É a busca do fenômeno, daquilo que surge por si só, daquilo que aparece, que se revela. Fenomenologia é ir às coisas mesmas, descobri-las tais quais se apresentam aos meus sentidos, tais quais eu as percebo. Mas é um ir em busca aliado à minha própria experiência subjetiva concreta. É um olhar e ver, não apenas uma colocação diante de algo. É participação, envolvimento.

Assim sendo, a Fenomenologia torna-se um modo de existir, de se colocar no mundo, de fazer parte deste mundo. Neste contexto, temos o ser humano também como um fenômeno. $\mathrm{O}$ mais complexo (talvez), mas o mais completo também.

A Fenomenologia resta, pois, um método de evidenciação, uma forma de renovação dos problemas filosóficos, mas o que temos como primordial na Fenomenologia é o seu caráter de contínua reflexão crítica, de re-pensar o mundo e a realidade, pois afinal, o ser somente se completa no seu devir, no seu crescer. 13

\section{Elementos para uma Fenomenologia}

Um dos aspectos centrais da Fenomenologia é a própria abordagem do que seja o fenômeno. O fenômeno, ou melhor, aquilo que se revela, que aparece, não pode e não deve ser considerado independentemente das experiências concretas de cada indivíduo.

Na realidade, o esforço da Fenomenologia reside na tarefa de ir às coisas mesmas ("zur Sache selbst"), ou seja, apreender o mundo tal qual este se apresenta para nós enquanto fenômeno.

O objeto nesta concepção é sempre um objeto-para-uma-consciência, em que não se

12. Merleau-Ponty, 1976:I.

13. Esta concepção fica mais clara com Heidegger, quando este assinala que, fundamentalmente, o sujeito e o mundo não são entidades separadas ou estáticas, sendo que o sujeito somente se deixa apreender por sua inserção no mundo, o que leva à concepção de que "...o indivíduo... sempre se encontra em transição, em evolução; é um ser emergente nunca fixado, nunca estabelecido, mas modelador do mundo através de interações constantes; sempre em devir, o seu desenvolvimento é marcado pela trama histórica da sua temporalidade, através da qual ele tem que elaborar o sentido pessoal da sua existência" (Bucher, 1989:30). 
pode desvincular a consciência do objeto e viceversa. A análise fenomenológica nos coloca diante da busca dos dados que precedem a reflexão científica, caracterizada basicamente pela concepção apriorística da realidade. Essa busca é assinalada pela tarefa primeira de "ir às coisas mesmas" e, assim, desvinculado de preconceitos, atingir o ponto mais essencial do objeto.

Vale a pena refletir sobre um aspecto que nos atinge sobremaneira como pessoas humanas, e mais particularmente, que é sumamente importante para o trabalho de psicoterapeutas: trata-se da extrema dificuldade de permanecer diante das coisas, sem o risco de misturar-se com elas; postura de observador não-intervencionista, que se coloca à distância e assim capta com mais precisão a realidade. 14

A esta postura dá-se o nome de redução fenomenológica, que é uma proposição de Husserl para que se faça uma redução entre "a existência de toda vivência e a própria subjetividade do eu vivencial". 15 É isto que permite pôr em evidência o ser-no-mundo. O fenômeno é um dado absoluto, e deve ser visto como tal, como uma expressão de uma essência que subjaz a ele. Para se compreender o fenômeno é preciso renunciar a tudo o que é particular do sujeito, de modo que lhe seja permitido uma maior liberdade na compreensão da realidade deste fenômeno.

A "redução fenomenológica" implica uma abstração das idéias pré-estabelecidas em prol de um contato direto com o observado e com o vivido. Desta maneira, sem elementos perturbadores, a apreensão do mundo surge mais clara e límpida.
Segundo Husserl, é preciso realizar a époché fenomenológica, ou seja, pôr o mundo entre parênteses, suspender todo e qualquer juízo da realidade. Não afirmar ou mesmo negar algo, 16 mas antes, deixar-se abandonar à compreensão desta realidade, que assim estaríamos voltando às coisas mesmas.

"Quando procedo assim, (...), eu não nego este "mundo", como se fosse um sofista; eu não coloco sua existência em dúvida, como se fosse um cético; mas eu opero a époché "fenomenológica"que me impede de todo julgamento sobre a existência espácio-temporal. Em consequência, todas as ciências que se reportam a este mundo natural - (...) - eu as ponho fora de circuito, não faço absolutamente nenhum uso de sua validade; não faço minhas nenhuma das suas proposições, fossem mesmo de uma evidência perfeita; não acolho nenhuma, nenhuma me dá fundamentos...". 17

A redução fenomenológica evidencia a colocação do ser-no-mundo, o posicionamento do ser em situação, em função da qual este sujeito não é puro sujeito, nem o mundo puro objeto. Ambos se correlacionam, permanecendo um em função do outro.

Redução é uma busca do significado, uma procura pelo subjacente, em detrimento do simples aparente. A conseqüência da époché é a intuição das essências ("Wessensschau"). Afi-

14. Ribeiro, 1985.

15. Ribeiro, 1985:46.

16. Husserl parte do ego solipsista (um eu-pensante, fechado em sua racionalidade, em sua consciência individual definidora, um ego-cogito) de Descartes para determinar uma nova relação do ego enquanto um ego-cogito-cogitatum, que designa que, através da consciência intencional, se estabelece uma ligação intrínseca entre o sujeito e o objeto. Desta feita, a relação sujeito-objeto se define em si própria, e não mais em seus elementos. Isto permite, para a Psicologia, uma retomada do ser humano numa perspectiva de um devir heraclítico (Holanda, 1993).

17. Husserl, 1985:102-103. 
nal, Fenomenologia não é apenas descrição do fenômeno, do aparente. Isto seria realizar um simples fenomenismo. Mas antes, fazer fenomenologia é realmente se embrenhar por dentro da realidade, para desvendar o que está por detrás desta realidade.

Para Merleau-Ponty, a Psicologia fenomenológica é a pesquisa das essências ou do sentido, e que quando levada aos seus limites, a psicologia eidética se torna analítico-existencial. Uma psicologia eidética deve situar o sujeito como presença no mundo. A redução é a maneira de se acessar o fenômeno tal qual ele é.

\section{“A redução não é uma abstração} relativamente ao mundo e ao sujeito, mas uma mudança de atitude - da natural para a fenomenológica - que nos permite visualizá-los como fenômeno, ou como constituintes de uma totalidade, no seio da qual o mundo e o sujeito revelam-se, reciprocamente, como significações". 18

A Fenomenologia visa pois buscar a essência mesma das coisas, e para a efetivação desta tarefa, procura descrever a experiência tal qual ela surge e tal qual ela se processa. A redução põe em evidência o ser-no-mundo, 19 o ser que se coloca em situação, em função do qual o sujeito não é puramente sujeito, nem o objeto é puro objeto, pois há uma intrínseca correlação entre ambos, visto a consciência fenomenológica ser uma consciência intencional.

A intencionalidade da consciência é uma das teses emprestadas por Husserl a Brentano, e significa que toda consciência é não somente consciência, mas também consciência de alguma coisa, assinalando assim uma relação com o

\footnotetext{
18. Forghieri, 1993:15.

19. Ribeiro, 1985.

20. Levinas, 1989.

21. Bucher, 1983:34.
}

objeto. Em suma, a intencionalidade apresentase como a própria essência da consciência. 20

A consciência é consciência ativa; cabe a ela dar sentido às coisas, ou seja, é a consciência que atribui significados no mundo. Perceba-se aqui que não estamos discutindo o caráter da existência das coisas (como colocado anteriormente por Husserl), mas tão somente o sentido que estas coisas assumem para o eu subjetivo pensante. Esta talvez seja a característica prática mais fundamental da fenomenologia husserliana. Ao mesmo tempo que a consciência é ativa, ela não ocorre no vazio; portanto, é consciência intencional. Além disso, só é consciência quando voltada-para-um-objeto; e este somente tem sentido de objeto, quando é objeto-para-uma-consciência.

O projeto de Husserl para a filosofia consiste em:

“...fundar-e fundamentar-, pela análise intencional, as significações vividas das pessoas, bem como os conceitos constituídos. Para realizar este projeto, a razão especulativa deveria seguir dois caminhos, complementares: por uma análise regressiva, voltar-se para si mesma para refazer a gênese de suas intencionalidades, a partir de sua arqueologia pré-teórica e pré-objetiva; por uma redução constitutiva, ascender ao mundo da consciência pura e das suas unidades transcendentais. Porém, nos dois caminhos o objetivo é o mesmo: apreender, possuir e explicar intelectualmente os sentidos que o mundo nos oferece". 21 
Um derradeiro conceito, que é capital para a Psicologia, é o de campo fenomenológico. Uma citação talvez esclareça este conceito:

“...todo comportamento, sem exceção, está inteiramente em função do campo fenomenológico, onde o organismo atua. O campo fenomenológico consiste na totalidade de experiências das quais a pessoa toma consciência no momento da ação. Essa tomada de consciência pode variar de um nivel mais baixo a um mais elevado, embora se presuma que nunca possa chegar a ser completamente inconsciente". 22

Este modelo de pensamento acarreta importantes conseqüências para a nossa compreensão da Psicologia como um todo. Uma delas é que convém assinalar uma significativa distinção entre o "pré-conceito" e o "conceito". O "pré-conceito" é produto de uma antecipação, da ante-visão de uma possibilidade, ou seja, é um a priori. Já o conceito é fruto da relação do sujeito com sua realidade vivencial, é um produto a posteriori.

Com relação à redução fenomenológica, podemos observar que, além da dificuldade natural de nos mantermos numa postura distanciada de nossos valores, há ainda a possibilidade de um outro erro, a total abstenção de participação, ou seja, o distanciamento indiscriminado da relação com o mundo e a realidade. Ou seja, redução não significa abstenção de relação ou anulação de valores ou idéias, mas tão somente suspensão temporária destes valores ou idéias no intuito de aproximar o sujeito pensante da efetiva realidade do objeto, e não da concepção suposta deste. Esta é a real tarefa da fenomenologia.

\section{Atitude Fenomenológica e Psicoterapia}

"À fenomenologia compete apresentar de maneira viva, analisar em suas relações de parentesco, delimitar, distinguir da forma mais precisa possível e designar com termos fixos os estados psíquicos que os pacientes realmente vivenciam. Visto que não se pode perceber diretamente um fenômeno psíquico de outrem, assim como se percebe um fenômeno físico, só se poderá tratar de representação, empatia e compreensão, a que poderemos chegar, segundo o caso, pelo meio de levantamento de uma série de caracteres e símbolos sensivelmente perceptiveis, por uma espécie de exposição sugestiva". 23

Esta colocação de Jaspers serve-nos de introdução à questão da aplicação da Fenomenologia à situação específica da psicoterapia. Uma análise fenomenológica nos posiciona, na qualidade de psicoterapeutas, diante da pessoa do cliente que vem até nós em busca de auxílio, de esclarecimento.

Segundo Bucher, 24 a Fenomenologia auxilia na compreensão dos processos de interação psicoterapêutica pela análise da intersubjetividade e da colocação do ser-no-mundo.

A Fenomenologia, aplicada à Psicologia, pode ser entendida como uma postura, uma atitude que nos abre todo um leque de possibilidades para plenificar o encontro com o fenômeno.

22. Snygg \& Combs, apud Ribeiro, 1985:51.

23. Jaspers, 1987:71.

24. Bucher, 1989. Numa perspectiva da fenomenologia heideggeriana. 
Uma reflexão sucinta sobre nossa dificuldade em nos postar sem misturas, sem amálgamas, diante das coisas, numa posição de observador que participa, mas não interfere, é uma proposição da Fenomenologia para a Psicoterapia.

$\mathrm{Na}$ específica situação de psicoterapia, temos uma situação na qual o nosso campo fenomenológico interage com o campo fenomenológico de outrem, partilhamos experiências semelhantes e sentimentos mútuos, mas não podemos trocar simplesmente de posição um com o outro. Não sendo possível esta troca, então não podemos afirmar nada para este outro, pois isto seria tão somente uma projeção minha no campo fenomenal do outro.

Mas, se nos postarmos numa atitude de escuta ativa, de espera, de observação atenta, no sentido de permitir o acesso do fenômeno à nossa consciência, eis que este surge, pois o fenômeno aparece, revela-se. Uma atitude interpretativa, uma consciência apriorística, somente serviriam para criar obstáculos à nossa consciência.

Essa tarefa realiza-se por meio da redução fenomenológica, no sentido de me encontrar com o cliente nele, com ele e através dele, 25 como fenômeno. Significa abrir-me para perceber-lhe a essência, descobrir-lhe a totalidade.

Uma atitude fenomenológica difere radicalmente de uma atitude fenomenista. Fazer fenomenologia é embrenhar-se num questionamento contínuo, ininterrupto. Fazer fenomenismo é ficar no campo das simples descrições das aparências. Encarar a emoção do cliente como uma mera expressão sintomática é colocar-se no plano do simples fenomenismo; inseri-la dentro da totalidade de sua existência é assumir uma postura crítica fenomenológica. Eis um exemplo:

"Estou pensando, especificamente, em certos trabalhos de corpo ou com o corpo, em que o gestaltista pode reduzir-se a um simples fenomenista, isto é, lidar com o que acontece, com as aparências de uma emoção, por exemplo, sem colocar este fenômeno dentro de um ser maior, sem perceber o sentido existencial daquela emoção com o restante da totalidade do cliente. Trata-se de uma ação sobre a aparência da aparência. Assim como a fenomenologia, a ação psicoterapêutica não pode ser uma simples descrição do que se ve, mas uma interrogação do todo que aparece...". 26

Em suma, se prestarmos atenção ao cliente, este se nos revela, não apenas em partes, mas na sua totalidade. As partes são objeto das ciências. $\mathrm{O}$ terapeuta que assume uma postura fenomenológica torna-se um verdadeiro facilitador da emergência do ser de seu cliente, um facilitador do fenômeno-cliente, pois sabe que ninguém melhor do que ele mesmo para interpretar a sua própria realidade. 27 A Fenomenologia é a valorização do encontro, do presente, do momento em que este ocorre, do aqui-e-agora.

O primordial de uma atitude fenomenológica é não encarar o cliente como um objeto ("o doente" que vem a ser "tratado"), mas uma pessoa, no mesmo nível existencial do terapeuta. Esta valorização do encontro, do "estar junto" no presente, é o que determina a diferença entre a relação médica (unidirecional, caracteri-

\section{Ribeiro, 1985.}

26. Ribeiro, 1985:45.

27. Esta é uma posição explicitamente defendida por Carl Rogers e pelos psicólogos humanistas em geral, bem como pela vertente existencial de psicoterapia. 
zada pelo uso de agentes intermediários, físicos ou bioquímicos, que são "aplicados" a um "paciente" que se submete ao tratamento) e a relação psicoterápica (que se caracteriza pela relação direta, cujo meio é o próprio "ambiente humano", na condição do diálogo, dia-logos, humano). 28

\section{A Influência da Fenomenologia sobre a Psicologia Humanista}

Talvez uma boa maneira de se entender a importância da Fenomenologia para a Psicologia em geral, e para a Psicologia Humanista em particular, seja com base no estudos que Keen 29 elabora. Para o autor, a Psicologia Fenomenológica pode ser encarada sob quatro aspectos: 1) Como uma fonte de hipóteses; 2) um veículo para o humanismo; 3) um novo paradigma e, 4) uma resposta à crise.

Como "fonte de hipóteses", a Fenomenologia surge como uma metodologia alternativa à ciência natural, principalmente no que tange a questões tais como intuições, sensações ou outros processos que não são comumente incluídos na lista de questionamentos científicos, mas que são "fenomenológicos num sentido informal e assistemático".

Em um nível mais específico, a Fenomenologia - cuja preocupação básica é a experiência - surge como uma metodologia importante, dado que:

$$
\text { “As reduções fenomenológi- }
$$

cas, variações imaginárias e interpretações têm sido sempre o capital de giro de cientistas, mas estes não as explicitaram de forma detalhada como procedimentos metodológicos. No nível mais simples de contribuição, a feromenologia pode fornecer uma descrição clara e algum rigor metodológico a este estágio crucial, $e$ tão negligenciado, do processo cientifico". 30

Podemos observar um crescente desenvolvimento das pesquisas qualitativas em Psicologia, envolvendo diversas metodologias, nas quais incluem-se a pesquisa fenomenológi$\mathrm{ca}^{31}$ e a análise fenomenológica. Este crescimento é louvável por apresentar-se na "perspectiva de um refinamento metodológico e na conseqüente oportunidade de considerar manifestações ou expressões humanas e sociais antes inacessíveis para estudo sistemático".32 Visa a obtenção de um critério "empírico, operacional, rigoroso e humano de ciência". O objetivo central de uma pesquisa nesta direção é de dar conta de dimensões do vivido humano não mensuráveis pela metodologia quantitativa tradicional.

As formas de investigação do humano são, essencialmente, modos de ser humanos, como a cultura, a poesia, o teatro etc. 33 Para se realizar uma pesquisa neste sentido, faz-se mister a utilização de um método de descrição e de análise de processos que seja compatível com a tradição da Psicologia Humanista, a fim de valorizar aspectos da intersubjetividade humana.

A investigação do humano tem de dar conta da originalidade deste humano: O que é próprio do humano não se deixa captar pelos métodos da ciência. ${ }^{34}$ As investigações das

28. Bucher, 1989.

29. Keen, 1979.

30. Keen, 1979:98.

31. Amatuzzi, 1992, 1994, 1995, 1996; Chaves, Macedo \& Mendonça, 1996.

32. Gomes, 1989.

33. Amatuzzi, 1994.

34. Amatuzzi, 1994. 
ciências humanas são do tipo sujeito-sujeito, ou subjetividade-subjetividade, ou melhor dizendo, relacionais, como assinala Buber com seu Eu e Tu. É a busca de significados. Ao contrário da ciência tradicional, em vez de fatos, temos fenômenos. Fatos somente são obtidos por abstração. Fenômenos são vividos.

Neste sentido, faz-se necessário uma psicologia fenomenológica, cujo fundamento é a valorização da subjetividade consciente e suas inter-relações. A psicologia fenomenológica, tendo como preocupação a experiência consciente, difere do método introspectivo pelo fato deste último estar interessado nos elementos mentais, ou seja, por tratar-se de um método reducionista, não se atendo, pois, à relação entre o objeto do estímulo e o significado da experiência. 35

A psicologia fenomenológica constituise num conjunto de procedimentos para a exploração da consciência imediata e da experiência. "Husserl reconhece a necessidade de uma psicologia, mas que é possivel somente através de descrição da experiência imediata enquanto manifesta na consciência em sua pureza. Por pureza, Husserl refere-se à suspensão de qualquer pressuposição teórica ou experimental como ponto inicial de análise".36 Assim, a psicologia fenomenológica é descritiva, eidética e empírica, além de intencional e transcendental:

\section{"É eidética, porque é uma re-}

flexão em que as generalidades e as tipicalidades do dado psicológico (experiência) aparecem sem a interferência dos pensamentos e valores momentâneos. É empírica, porque identifica essências pré-existentes. $\dot{E}$ in- tencional, porque revela a consciência, que constitui a organização da experiência". 37

Como um "veículo para o humanismo", a Fenomenologia coloca em seu centro de atenção a consciência. Ao focalizar a experiência do indivíduo, a Psicologia atua fenomenológica e humanisticamente. É relevante, contudo, o fato de que o humanismo carece de método, de uma teoria coerente e de uma estrita fundamentação de dados. Além disso, a finalidade do humanismo (compreensão) difere dos fins científicos (previsão e controle). A Fenomenologia pode ser um excelente veículo de comunicação entre o Humanismo e a Ciência tradicional, ao possibilitar revelar, de forma organizada e metódica, o mundo privado do indíviduo.

\section{"[A Psicologia Fenomenoló-} gica] em seus momentos mais ambiciosos, aspira a estabelecer um novo paradigma para a psicologia. Este novo paradigma envolverá uma modificação quanto a quais fatos e teorias são importantes: que perguntas formular, quais respostas considerar como tais e, em geral, quais os objetivos da ciência". 38

Por fim, a proposta husserliana e a Fenomenologia procuram responder à crise de valores erigida no pensamento moderno - herdeiro e devedor da metafísica dicotômica. A antiga separação sujeito/objeto, ou mesmo a herança maniqueísta, são exemplos desta crise atual.

Uma psicologia fenomenológica procura revelar o ser humano para si próprio, fazendo-o

35. Gomes, 1985.

36. Gomes, 1985:137.

37. Gomes, 1985:137.

38. Keen, 1979:101. 
observar-se e aos demais, refletir sobre si próprio e sobre suas observações. "Mais explicitamente, o objetivo da psicologia fenomenológica é revelar à nossa compreensão explícita aquilo que já compreendíamos implicitamente (...) nossa compreensão diária, vivida, de nós mesmos, não é abordada por nossas teorias psicológicas".39

Diante disto tudo, percebe-se que as intuições de Husserl possuem ramificações profundas dentro do âmbito do pensamento psicológico. Talvez a principal ramificação, oriunda diretamente da filosofia, seja a disciplina desenvolvida por seu discípulo e sucessor na Alemanha, Martin Heidegger.

Heidegger procurou estabelecer uma ontologia com base no método husserliano, e termina por criar a Daseinanalytik, ou Analítica Existencial, cuja obra de referência capital é o Ser e Tempo, de 1927.

$$
\text { "As idéias de Heidegger }
$$
conheceram rapidamente aplicações em estudos psicopatológicos e na psiquiatria, nos quais se tentou revelar metamorfoses particulares desta estrutura ontológica e dos seus determinantes. Trabalhos sobre espacialidade, historicidade, disposição afetiva, percepção do desenrolar temporal, sonhos e outras dimensões da existência e suas mutações em estados psicopatológicos foram publicados em vários paises (Minkowski e Bachelard na França; Binswanger, Strauss, Gebsattel e outros na Alemanha; Buytendijk e Van den Berg na Holanda... ". 40

De todos esses nomes, talvez o de maior expressão e penetração no campo psicoterápico seja o de Ludwig Binswanger que, com base no prisma heideggeriano, propõe uma escola própria de pensamento psicoterápico, que se intitula Daseinanalyse ou Análise Existencial. É uma nova maneira de abordar a psicoterapia, em que a doença importa menos do que o indivíduo em questão. Trata-se de um movimento existencial e de um esboço do mundo, uma tentativa de compreender a maneira de ser do cliente. 41 Binswanger delimita uma "fenomenologia antropológica" que se preocupa com a totalidade do ser humano, na sua normalidade e anormalidade, na qualidade de um ser que se experiencia em relação com o mundo. 42

Esta escola conhece grande desenvolvimento a partir dos trabalhos de Medard Boss e de Rollo May (além de Storch, Bally e Roland Khun, apenas para citar alguns). Posteriormente vem a ser modificada e ramificada noutra escola psicoterápica, na figura do psiquiatra vienense Viktor Frankl, que aponta para uma evolução da análise existencial até alcançar a chamada Logoterapia.

Nesta linha mais existencialista, temos de citar o brilhante trabalho de Karl Jaspers, que aponta para uma psicopatologia existencial.

39. Keen, 1979: 104.

40. Bucher, 1989:29.

41. Este movimento existencial em psiquiatria e psicopatologia é fruto de todo um processo de insatisfação iniciado com os trabalhos de Reich, Rank, Fromm e Horney, que desemboca em significativas mudanças na psicoterapia (May, 1967). Segundo Bucher (1983:37), "apesar de sua abertura para com a psicanálise, Binswanger permaneceu fiel à fenomenologia transcendental de Husserl. (...) Graças à concepção do "Dasein" de Heidegger, o conceito de consciência transcendental ligada a uma subjetividade pura, postulada à luz da estrutura da intencionalidade e do "Weltentwurf", do "projeto de mundo" desta consciência, tornava-se mais concreto, fornecendo assim a Binswanger a base para uma fundamentação filosófica da psiquiatria e permitindo a sua aplicação à análise dos modos de espacialidade, de temporalidade e da "Selbstigung", da "autorealização" da consciência, no seu "projeto de mundo" genuinamente próprio".

42. Gomes, 1986. 
Propõe uma relação pessoal entre médico e paciente, assinalando a responsabilidade do psiquiatra, para seu compromisso pessoal no trato com seu cliente. Jaspers foi um dos primeiros a considerar o delírio como uma forma de ser-nomundo, de perceber este mundo e de dar-lhe sentido.

Por outro lado, na França, as idéias existencialistas de Jean-Paul Sartre influenciam profundamente o movimento antipsiquiátrico preconizado por figuras como David Cooper e Ronald Laing.

A Fenomenologia, propriamente dita, atinge fundamentalmente a corrente dita "humanista" de psicoterapia, que preconiza a consideração da totalidade do ser do cliente, o posicionamento do terapeuta de um modo mais ativo na relação, ou seja, o terapeuta como um existente que se coloca em relação com o seu cliente, em contraposição a uma postura mais distanciada, mais analítica e menos vivencial, menos intersubjetiva, além de outros elementos.

Diríamos que, fundamentalmente, a Abordagem Centrada na Pessoa e um modelo de Gestalt-Terapia ${ }^{43}$ poderiam ser considerados como abordagens de cunho fenomenológico. Isto se deve ao fato de haver aí uma consideração de que a fonte de todo conhecimento autêntico está na experiência imediata de si e de outrem; apontam para uma atitude terapêutica desprovida de idéias apriorísticas e fundamentam suas relações no momento do aquie-agora, no presente, na presença do terapeuta como um ser existente aberto à relação, ou seja, o terapeuta, neste sentido, é muito mais "pessoa" (como assinala Rogers) do que propriamente um papel a ser desempenhado.
Embora a expressão "aqui-e-agora" já tenha conotações populares diversas, consideramos aqui alguns aspectos centrais a serem observados. Uma relação calcada no "aqui-eagora" envolve, antes de tudo, abertura, totalidade e presença. Abertura para a possibilidade do encontro e da presença efetiva do ser na relação em sua totalidade. Com base nisto, estabelece-se uma relação imediata, ou seja, uma relação na qual não se interpõem meios entre o terapeuta e o cliente. Estas qualidades já são apontadas por Martin Buber, ${ }^{44}$ quando este fala do diálogo como realidade existencial.

Enfim, o que assinalamos foi tão somente uma pequena parte do desenvolvimento das idéias fenomenológicas e de suas aplicações no campo da psicologia. A Fenomenologia surge como "a" filosofia do século XX, como uma autêntica "revolução cartesiana", como o retorno ao "pré-reflexivo", como o resgate das essências da realidade que se havia esquecido anteriormente pelas filosofias pragmáticas e objetivistas, cuja preocupação residia apenas no progresso das idéias voltadas para o objeto, para o "ter" materialista e não para a essência e para a existência, para o "ser".

\section{Referências}

Abbagnano, N. (1992). Diccionário de la Filosofia, Mexico: Fondo de Cultura Económica.

Amatuzzi, M.M. (1992). O Silêncio e a Palavra, Estudos de Psicologia, Campinas, 9(3):77-96.

Amatuzzi, M.M. (1994). A Investigação do Humano: Um debate, Estudos de Psicologia, Campinas, 11(3):73-78.

43. A Gestalt-Terapia possui raízes filosóficas as mais variadas e, por vezes, conflitantes. Isto nos permite afirmar que não existe apenas uma, mas diversas "Gestalt-Terapias", cada uma compreendida a partir de um enfoque específico e de uma construção epistemológica. Já a Abordagem Centrada na Pessoa possui uma base mais fundamentada na Fenomenologia, mesmo que implicitamente.

44. Buber, 1979. 
Amatuzzi, M.M. (1995). Descrevendo Processos Pessoais, Estudos de Psicologia, Campinas, 12 (1):65-80.

Amatuzzi, M.M. (1996). Apontamentos Acerca da Pesquisa Fenomenológica, Estudos de Psicologia, 13 (1):5-10.

Bonin, W.F. (1991). Diccionario de los Grandes Psicólogos, Mexico: Fondo de Cultura Económica.

Boris, G.D.J.B. (1994). Noções Básicas de Fenomenologia, Insight-Psicoterapia, Nov.; pp.19-25.

Buber, M. (1979). Eu e Tu, São Paulo: Moraes.

Bucher, R.E. (1983). Fenomenologia e Psicanálise, Revista Brasiliense de Psiquiatria, 3/1:33-43.

Bucher, R.E. (1989). Psicoterapia pela Fala, São Paulo: EPU.

Chaves, A.P.; Macedo, S. \& Mendonça, V. (1996). Psicologia Existencial-Fenomenológica: O saber filosófico e a produção científica, Estudos de Psicologia, Campinas, 13(2):11-16.

Figueiredo, L.C. (1991). Matrizes do Pensamento Psicológico, Petrópolis: Vozes.

Forghieri, Y.C. (1993). Psicologia Fenomenológica. Fundamentos, Método e Pesquisas, São Paulo: Pioneira.

Frayze-Pereira, J.A. (1984). Apontamentos para uma Crítica da Psicologia Humanista, Psicologia, 10(3):1-10.

Giles, T.R. (1989). História do Existencialismo e da Fenomenologia, São Paulo: E.P.U.

Gomes, W.B. (1986). Influências da Fenomenologia e da Semiótica na Psicoterapia, Psico, Porto Alegre, 12(1):127-144.

Gomes, W.B. (1989). O Critério Metodológico da Fenomenologia Estrutural na Análise de Depoimentos, Psicologia, Reflexão e Crítica, Porto Alegre, 4(1/2):98-102.

Holanda, A.F. (1993). Carl Rogers e Martin Buber. Abordagem Centrada na Pessoa e Filosofia Dialógica em Questão, Universidade de Brasília, Dissertação de Mestrado.
Husserl, E. (1985). Idées Directrices pour une Phénoménologie et une Philosophie Phénoménologie Pures, Paris: Gallimard.

Husserl, E. (1992). Conferências de Paris, Lisboa: Edições 70.

Jaspers, K. (1987). Psicopatologia Geral, São Paulo: Livraria Atheneu.

Keen, E. (1979). Introdução à Psicologia Fenomenológica, Rio de Janeiro: Interamericana.

Levinas, E. (1989). Théorie de l'Intuition dans la Phénoménologie de Husserl, Paris: Librairie Philosophique J.Vrin.

May, R. (1967). Orígenes y Significado del Movimiento Existencial en Psicología, In: Rollo May, Ernest Angel \& Henri F.Ellenberger (Eds), Existencia, Madrid: Editorial Gredos S.A.

Merleau-Ponty, M. (1976). Prefácio, In: M.Merleau-Ponty, Phénoménologie de la Perception, Paris: Gallimard.

Ribeiro, J.P. (1985). Gestalt-Terapia. Refazendo um Caminho, São Paulo: Summus. 